\title{
Perfluoroalkyl substances in the Daling River with concentrated fluorine industries in China: seasonal variation, mass flow, and risk assessment
}

\author{
Zhaoyun Zhu • Tieyu Wang • Jing Meng • Pei Wang • \\ Qifeng Li • Yonglong Lu
}

Received: 17 November 2014 / Accepted: 29 January 2015 /Published online: 11 February 2015

(C) Springer-Verlag Berlin Heidelberg 2015

\begin{abstract}
In the present study, we investigated concentrations and composition profiles of perfluoroalkyl substances (PFASs) in surface water from the Daling River in different seasons. The highest concentration of $\Sigma$ PFASs $\left(9540 \mathrm{ng} \mathrm{L}^{-1}\right)$ and dominant homologues were found in surface water collected in summer. Perfluorobutanoic acid (PFBA), perfluorobutane sulfonate (PFBS), and perfluorooctanoic acid (PFOA) were the dominant PFASs in four seasons with a total contribution of over $90 \%$. The discharge of two fluorine chemical industry parks was predicted to be the main contamination source of PFASs in the study area. The daily and annual mass flows were calculated according to data of detected PFAS concentrations and water discharge, and the annual mass loading of PFASs into the Bohai Sea from the Daling River reached to $461 \mathrm{~kg} \mathrm{year}^{-1}$. Hazard assessment indicated that concentrations of PFASs in study area had little risk to aquatic organisms and wildlife. However, the multiple health risk would be relatively high if the water was served as drinking water in the study area.
\end{abstract}

Keywords PFASs · Seasonal variation - Source · Mass flow · Hazard assessment $\cdot$ Concentrated fluorine industries

Responsible editor: Leif Kronberg

Electronic supplementary material The online version of this article (doi:10.1007/s11356-015-4189-0) contains supplementary material, which is available to authorized users.

Z. Zhu $\cdot$ T. Wang $(\bowtie) \cdot J$. Meng $\cdot$ P. Wang $\cdot$ Q. Li $\cdot$ Y. Lu

State Key Lab of Urban and Regional Ecology, Research Center for

Eco-Environmental Sciences, Chinese Academy of Sciences,

Beijing 100085, China

e-mail: wangty@rcees.ac.cn

Z. Zhu $\cdot$ J. Meng $\cdot$ P. Wang $\cdot$ Q. Li

University of Chinese Academy of Sciences, Beijing 100049, China

\section{Introduction}

Perfluoroalkyl substances (PFASs) have been manufactured and used in many industrial products and manufacturing processes, such as lubricants, firefighting foams, stain-resistant treatments, and electroplating and coating additives, for more than 60 years (Giesy and Kannan 2002; Prevedouros et al. 2006). As a type of emerging persistent and bioaccumulative environmental contaminants, they have received great scientific concerns due to their ubiquitous environmental distribution (Ahrens 2011; Ahrens et al. 2011; Bao et al. 2010; Houde et al. 2011; Naile et al. 2010; Young et al. 2007) as well as their potential toxicity to ecological system and human (Lau et al. 2004; Olsen et al. 2009). Perfluorooctane sulfonate (PFOS) and related substances have been restricted by EU Directive 2006/122/EC and listed as persistent organic pollutants under the Stockholm Convention in recent years (EPC 2006; UNEP 2009). As for perfluorooctanoic acid (PFOA), national programs in the USA and Canada are attempting to regulate the use of PFOA, its salts, and precursors (US EPA 2006; Vierke et al. 2012). Short-chained $\mathrm{C}_{4}$-PFASs, such as perfluorobutane sulfonate (PFBS) and perfluorobutanoic acid (PFBA), have been introduced as substitute compounds for $\mathrm{C}_{8}$-PFASs, leading to the rapidly increased production of short-chained PFASs in recent years (Oliaei et al. 2013). As legislation for the production and use of PFOS as well as its related chemicals has become stricter in developed countries, China is now the main country offering PFOS-related chemicals, including PFBS and PFBA. Although the production of PFOS and PFOA is also restricted in China, they are still ubiquitous in the environment due to the huge demand for PFOS-containing products and industrial processes (Wang et al. 2009).

Previous studies have mainly focused on the occurrence and distribution of PFASs in environment (Shi et al. 2012; 
Theobald et al. 2012; Yamashita et al. 2005; Jin et al. 2009; Li et al. 2011; Pan et al. 2011; Shi et al. 2012; So et al. 2007). Spatial and temporal variations of PFASs on riverine levels can reflect the emission of PFASs from a watershed, and the estimation of discharge flux is useful to investigate the transportation of PFASs in river (McLachlan et al. 2007; Pistocchi and Loos 2009). It is essential to identify the sources, transport, and long-term pollution status of PFASs in water based on seasonal and comprehensive investigation in order to obtain information for sustainable management of PFASs in aquatic environment. A survey conducted by Tsuda et al. (2010) found the seasonal concentration changes of PFOS and PFOA in surface water of Akanoi Bay in Japan. Zhao et al. (2014) investigated the spatial distributions and seasonal variations of PFASs in surface water of Elbe River and lower Weser River in Germany, showing significant seasonal variation in concentrations of perfluorohexanoic acid (PFHxA) and PFOA in Elbe River. In addition, they also estimated the annual fluxes of PFASs into the North Sea in their study.

This work has become part of the systemic investigation on PFASs in environment of the Bohai and Yellow Seas since 2008. The highest concentration of PFASs has been found in both water body and surrounding soil along the Daling River area of the Bohai Bay, and two fluorine chemical parks are located along the Xi River (one of the biggest tributaries of the Daling River) in Fuxin City of Liaoning Province (Wang et al. 2012, 2013). The fluorine chemical facilities along the Daling River are the major manufacture centers in North China. Previous studies in this area have reported the occurrence and wide distribution of PFASs in surface water, sediment, soil, and human serum (Bao et al. 2011; Chen et al. 2011; Wang et al. 2011, 2013). The transportation of PFASs in river system is considered as the main environmental transport way of PFASs. Nowadays, little information is available about the seasonal pollution characteristics and transport behavior studies of PFASs in China's aquatic environment. In order to further understand the sources and transport flux of PFASs in the Daling River and its tributaries, it is necessary to examine PFAS concentrations in surface water in different seasons. In the present study, we focused on the seasonal characteristics of pollution and transportation of PFASs in the Daling River adjacent to typical fluorine industrial area. Our data provided more comprehensive information on long-term study of the source and transportation of PFASs and offered scientific support for management and risk assessment of PFASs.

\section{Materials and methods}

Study area

As one of the largest rivers in the west Bohai Bay, the Daling River has a length of $397 \mathrm{~km}$ with a drainage area of 23,
$263 \mathrm{~km}^{2}$. The Xi River, which converges into the Daling River at downstream, is one of the largest tributaries of the Daling River flowing through Fuxin City. Uneven distribution of precipitation (about $70 \%$ of the total rainfall occurs in summer) in the study area results in the significantly different streamflow in four seasons. In recent years, Fuxin City has been taking steps to develop the fluorochemical industry by establishing some fluorine chemical parks due to the local abundance of mineral fluorite $\left(\mathrm{CaF}_{2}\right)$, and it has become the main fluorochemical industry center in North China (Wang et al. 2013). Studies have reported the effect of PFAS emissions into the environment, which are absorbed by residents living near the parks (Bao et al. 2011; Liu et al. 2009; Wang et al. 2013). Therefore, it is essential to further assess the seasonal variations, source emissions, and transporting behavior of PFASs in this area.

\section{Sampling campaign}

Sampling campaign was conducted at the same 18 sampling sites along the Daling River in the first month of each season in 2013 (January in winter, April in spring, July in summer, and October in autumn, respectively) in order to examine seasonal variations. The study area was divided into four zones (zones A, B, C, and D) according to specific environment influential factors (Fig. S1). Zone A is the upstream of the $\mathrm{Xi}$ River, where no direct pollution source of PFAS is found. Zone $\mathrm{B}$ is the area with two fluorine chemical parks. Zone $\mathrm{C}$ is the downstream of the Daling River after the $\mathrm{Xi}$ River empties into it. Zone D is the upstream of the Daling River with water from the Baishi Reservoir. During each sampling campaign, 1-L surface water (top 1$20 \mathrm{~cm}$ ) was collected using a prerinsed polypropylene (PP) bottle. The surface film was excluded from the collected surface water. The collected water samples were kept on ice during transport (McLachlan et al. 2007) and stored at $4{ }^{\circ} \mathrm{C}$ prior to further analysis. No flood event or heavy rain happened during the sampling period.

Extraction and analysis of target analytes

Table S1 shows that a total of 11 PFASs, including eight perfluorocarboxylic acids (PFCAs) and three perfluorinated sulfonic acids (PFSAs), were qualified and quantified. Water samples $(400 \mathrm{~mL})$ were extracted using OASIS WAX-SPE according to previously described method with minor modifications (Wang et al. 2014a). Before water sample loading, 10-ng mass-labeled internal standards were spiked into samples and thoroughly mixed. Meanwhile, the Oasis WAX cartridges (size of $6 \mathrm{cc}, 150 \mathrm{mg}, 30 \mu \mathrm{m}$ ) were preconditioned with $4 \mathrm{~mL}$ of $0.1 \% \mathrm{NH}_{4} \mathrm{OH}$ in methanol, $4 \mathrm{~mL}$ of methanol, and $4 \mathrm{~mL}$ of Milli-Q water, respectively. After sample loading, 
cartridges were washed with $4 \mathrm{~mL}$ of $25 \mathrm{mM}$ ammonium acetate and then air-dried. Target analytes were then eluted with $4 \mathrm{~mL}$ of methanol and $4 \mathrm{~mL}$ of $0.1 \%$ $\mathrm{NH}_{4} \mathrm{OH}$ in methanol, respectively. The collected eluate was concentrated to $0.5 \mathrm{~mL}$ under a gentle stream of high purity nitrogen and passed through a nylon filter $(0.2 \mu \mathrm{m})$, and then it was transferred into a $1.5-\mathrm{mL}$ PP snap top brown glass. The instrumental analysis was performed with a high-performance liquid chromatography negative electrospray ionization-tandem mass spectrometry system. The instrumental conditions are listed in Table S2.

\section{QA/QC}

All fluorinated materials that could contact with the samples during sampling and extraction were removed to avoid contaminations. Field blanks, transport blanks, procedure blanks, and solvent blanks were conducted to make sure no external pollution occurred during the whole process. The limit of detection (LOD) and limit of quantification (LOQ) were defined as the peak of analyte required to yield a signal-to-noise $(\mathrm{S} / \mathrm{N})$ ratio of 3:1 and 10:1, respectively. In order to quantify individual PFAS with coefficients of determination $\left(r^{2}\right)$ for all the target analytes higher than 0.99 , nine-point external standard curves ranging from 0.01 to $100 \mathrm{ng} \mathrm{mL}^{-1}$ were prepared. Recoveries of internal standards spiked into water samples ranged from 74 to $109 \%$. LOD and LOQ of this method ranged from 0.01 to $0.13 \mathrm{ng} \mathrm{L}^{-1}$ and from 0.06 to $0.63 \mathrm{ng} \mathrm{L}^{-1}$, respectively. No detectable PFASs were observed over LOQ in all the blanks. Detailed QA/QC measurements of PFASs are given in Table S1.
Statistical analysis

Statistical analysis was performed with SPSS Statistics V21. Before analysis, concentration values lower than the LOQ were set to one half of the LOQ, and those lower than the LOD were assigned as values of the LOD $/ \sqrt{2}$ (Bao et al. 2010).

\section{Results and discussion}

Seasonal variation of PFASs in surface water of the Daling River

The presence of PFASs was confirmed in all analyzed water samples collected from the Daling River. However, the levels of PFASs varied in different seasons and study zones. Table 1 summarizes the concentrations of PFASs in surface water of the Daling River in four seasons. The $\Sigma$ PFAS concentrations in water samples of spring, summer, autumn, and winter ranged from 4.32 to $5010 \mathrm{ng} \mathrm{L}^{-1}$ (mean $1030 \mathrm{ng} \mathrm{L}^{-1}$ ), from 12.8 to $9540 \mathrm{ng} \mathrm{L}^{-1}$ (mean $2460 \mathrm{ng} \mathrm{L}^{-1}$ ), from 5.66 to $4800 \mathrm{ng} \mathrm{L}^{-1}$ (mean $1080 \mathrm{ng} \mathrm{L}^{-1}$ ), and from 1.77 to $2180 \mathrm{ng} \mathrm{L}^{-1}$ (mean $743 \mathrm{ng} \mathrm{L}^{-1}$ ), respectively. Generally, PFBS and PFBA were the predominant PFASs, followed by PFOA. The seasonal variations were assessed according to the average concentration of $\Sigma$ PFASs calculated based on season. A relatively clear seasonal trend was observed, showing that the average concentration of $\Sigma$ PFASs in summer was the highest, followed by autumn, spring, and winter. The average concentration of $\Sigma$ PFASs in summer was about two times higher compared with spring and autumn, and three times higher compared with winter. PFBS, PFBA, and PFOA all

Table 1 PFAS concentrations in seasonal water samples from the Daling River (ng L ${ }^{-1}$ )

\begin{tabular}{|c|c|c|c|c|c|}
\hline Analyte & $n$ & $\begin{array}{l}\text { Spring } \\
\text { Mean (min, max) }\end{array}$ & $\begin{array}{l}\text { Summer } \\
\text { Mean (min, max) }\end{array}$ & $\begin{array}{l}\text { Autumn } \\
\text { Mean (min, max) }\end{array}$ & $\begin{array}{l}\text { Winter } \\
\text { Mean (min, max) }\end{array}$ \\
\hline PFBA & 18 & $351(1.36,1970)$ & $679(5.78,2430)$ & $292(<\mathrm{LOD}, 1570)$ & $244(<\mathrm{LOD}, 628)$ \\
\hline PFOA & 18 & $150(0.47,749)$ & $523(2.51,2280)$ & $210(<\mathrm{LOD}, 675)$ & $202(0.27,753)$ \\
\hline PFPeA & 18 & $15.7(0.03,79.6)$ & $63.4(0.28,273)$ & $20.7(<\mathrm{LOD}, 81.2)$ & $45.9(<\mathrm{LOD}, 139)$ \\
\hline PFHxA & 18 & $32.8(0.02,168)$ & $129(0.46,603)$ & $55.1(<\mathrm{LOD}, 180)$ & $53.3(<\mathrm{LOD}, 183)$ \\
\hline PFHpA & 18 & $8.53(0.11,36.8)$ & $28.2(0.38,119)$ & $13.4(<\mathrm{LOD}, 45.5)$ & $9.67(<\mathrm{LOD}, 29.4)$ \\
\hline PFNA & 18 & $4.36(0.09,20.1)$ & $4.41(0.70,9.17)$ & $5.68(<\mathrm{LOD}, 19.9)$ & $1.12(<\mathrm{LOD}, 2.95)$ \\
\hline PFDA & 18 & $2.92(<\mathrm{LOD}, 15.5)$ & $3.44(<\mathrm{LOD}, 15.0)$ & $3.10(<\mathrm{LOD}, 8.13)$ & $1.11(<\mathrm{LOD}, 3.98)$ \\
\hline PFUdA & 18 & $0.14(0.02,0.48)$ & $0.23(<\mathrm{LOD}, 0.44)$ & $0.25(<\mathrm{LOD}, 0.43)$ & $0.22(<\mathrm{LOD}, 0.22)$ \\
\hline PFBS & 18 & $409(0.06,1980)$ & $1080(<\mathrm{LOD}, 3870)$ & $516(0.47,2341)$ & $209(0.04,689)$ \\
\hline PFOS & 18 & $54.0(0.59,483)$ & $3.99(1.02,21.2)$ & $0.89(0.16,2.27)$ & $7.94(0.87,39.9)$ \\
\hline PFHxS & 18 & $0.51(0.04,2.48)$ & $1.66(<\mathrm{LOD}, 4.34)$ & $0.49(<\mathrm{LOD}, 1.47)$ & $0.51(<\mathrm{LOD}, 1.16)$ \\
\hline PFCAs & 18 & $565(2.37,3030)$ & $1430(10.9,5660)$ & $566(0.00,2460)$ & $525(0.27,1680)$ \\
\hline PFSAs & 18 & $463(0.75,1980)$ & $1030(1.84,3880)$ & $517(0.97,2340)$ & $217(1.51,701)$ \\
\hline$\Sigma$ PFASs & 18 & $1030(4.32,5010)$ & $2460(12.8,9540)$ & $1080(5.66,4800)$ & $743(1.77,2180)$ \\
\hline
\end{tabular}

$n$ number of samples, $\angle L O D$ below the limit of detection 
presented the higher concentrations in summer compared with other seasons, with mean of 1080, 679, and $523 \mathrm{ng} \mathrm{L}^{-1}$, respectively. However, PFOS showed different phenomena with high concentrations found in spring ranging from 0.59 to $483 \mathrm{ng} \mathrm{L}^{-1}$ (mean $54.0 \mathrm{ng} \mathrm{L}^{-1}$ ).

Figure 1 exhibits spatial distributions and seasonal variations of total and individual PFAS in water. In general, the levels of PFASs significantly varied in the four zones. For all four seasons, the highest concentration of $\Sigma$ PFASs was detected in zone $\mathrm{B}$, followed by zone $\mathrm{C}$, zone $\mathrm{A}$, and zone D. Zone $\mathrm{B}$ and zone $\mathrm{C}$ exhibited a quite similar seasonal variation trend, showing the highest concentration in summer, followed by autumn, spring, and winter. The average concentration of $\Sigma$ PFASs in zone B was approximately five times higher compared with zone $\mathrm{C}$, more than one order of magnitude higher compared with zone $\mathrm{A}$ and more than two orders of magnitude higher compared with zone D.

PFBS was the dominant homologue of PFAS in samples from zone B and zone C. Bao et al. (2011) reported that one of the industrial parks specializes in the manufacture of potassium perfluorobutane sulfonate (KPFBS) and fluoropolymers in zone B. Wang et al. (2013) also found that KPFBS and perfluorobutanesulfonyl fluoride (PFBSF) are produced by electrochemical fluorination (ECF) process of the two parks. It indicated that the fluorine chemical parks located in zone B were the main point sources of PFASs, especially PFBS, as the PFAS levels in zone $\mathrm{B}$ and zone $\mathrm{C}$ were greatly affected by the emissions of fluorine chemical parks. Meanwhile, historically, ECF was used to synthesize PFOS and PFOA, with about 70$80 \%$ linear and 20-30\% branched isomers respectively. As a primitive technology, ECF would also generate complex mixtures of homologues with 4 to 9 carbons and other intermediates or by-products (Paul et al. 2009). This is why relatively high concentrations of PFOS and PFOA are still detected in this area. The seasonal distribution trend was little different in zone A and zone D. Water in zone A had relatively high $\Sigma$ PFAS concentrations in autumn and winter, while in zone D, the relatively high SPFAS concentrations were found in summer and winter. Considering the location, zone A allocated at the upstream of the fluorine chemical parks, but downstream of Fuxin City; then, domestic emissions of human activities from the city should be an important source (Xie et al. 2013a).

Composition profiles of PFASs in seasonal water of the Daling River

The composition profiles of main PFAS homologues in seasonal water from the four zones are shown in Fig. S2. In zone A, PFBA was the dominant PFASs in summer, autumn, and winter water samples with a contribution of $43-55 \%$ to total
Fig. 1 Levels of PFAS

concentrations in seasonal water samples from four zones

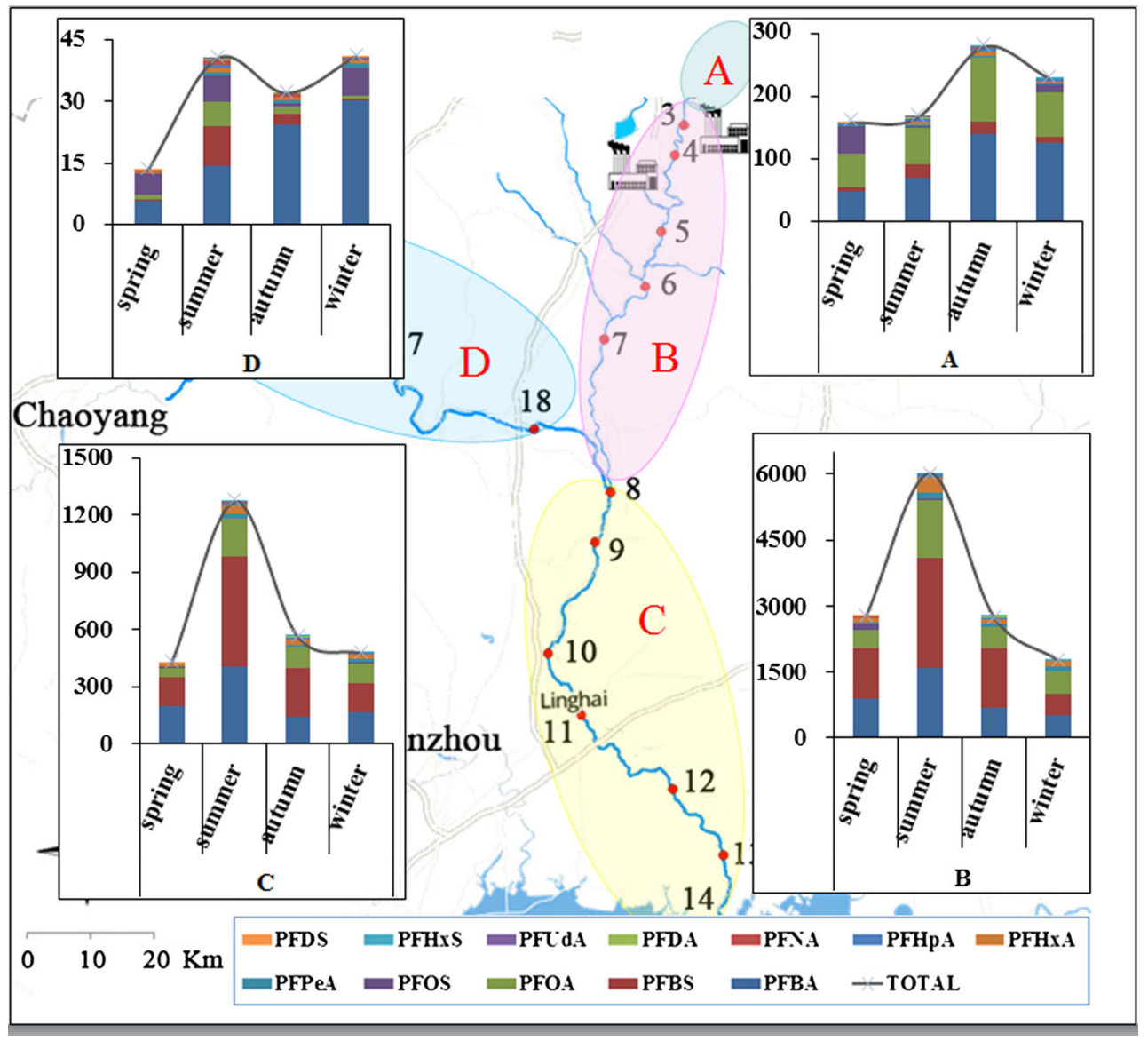


PFASs, followed by PFOA with a contribution of $31-37 \%$ to total PFASs. Major components in spring water samples were PFOA, PFBA, and PFOS with a contribution to total PFASs of 34,31 , and $28 \%$, respectively. In zone $\mathrm{B}$, the dominant component was PFBS with a contribution of 29-50\% to total PFASs in four seasons. Other major components included PFBA and PFOA, accounting for 24-32 and 15-29\% of total PFASs, respectively. Similar to zone B, PFBS, PFBA, and PFOA were the major components in seasonal water samples of zone C (spring, PFBS $35 \%$, PFBA $47 \%$, PFOA $11 \%$; summer, PFBS $46 \%$, PFBA $32 \%$, PFOA $15 \%$; autumn, PFBS $46 \%$, PFBA $26 \%$, PFOA $19 \%$; winter PFBS $32 \%$, PFBA $35 \%$, PFOA $21 \%$ ). The PFAS composition profiles in water samples of zone D were quite different from other zones. Although PFBA was still the dominant homologue (spring $45 \%$, summer $35 \%$, autumn $76 \%$, winter $74 \%$ ), the proportion of PFOS was up to $39 \%$ in spring, $16 \%$ in summer, and $17 \%$ in winter. The PFOS proportion in seasonal water samples of other three zones was less than $10 \%$ (except for spring water samples from zone A).

Generally, short-chained PFASs (PFBS and PFBA) were the dominant homologues in seasonal water samples in the study area. PFBS and PFBA have been introduced as substitute compounds for C-8 PFASs due to the phase-out of PFOSbased products by $3 \mathrm{M}$ in 2002 (OECD 2002), the restriction of PFOS or related chemicals in industrial and consumer products by international organizations (EPC 2006; UNEP 2009), and the restriction of PFOA use by the US EPA 2010/15 PFOA Stewardship Program in 2006 (US EPA 2006). PFBS has been reported as the dominant compound along the River Rhine with local hot spots in 2006 and 2007 (Skutlarek et al. 2006; Lange et al. 2007), and relatively high concentrations of PFBS and PFBA have been reported in subsequent several years in German environment (Möller et al. 2010; Eschauzier et al. 2012; Dreyer et al. 2009). Several years ago, studies in the Daling River area showed that PFOA and PFOS were predominantly detected compounds (Bao et al. 2011; Wang et al. 2011), but PFBA and PFBS are the predominate ones nowadays. Relevant studies also found high concentrations of short-chained PFASs in some wastewater treatment plants in China (Zhang et al. 2013). This indicated that short-chained PFASs have been produced and applied more and more widely as substitutes worldwide.

Source identification of PFASs along the Daling River

Although no fluorinated chemical manufacturers were located in zone $\mathrm{A}$, the emerging automobile industry in this region might be a potential source of PFASs since fluorinated chemicals are used in rubber tires and car wax. Transportation-related emission may be nonpoint sources of PFASs into environment (Zushi and Masunaga 2009). In zone $\mathrm{B}$, there were two fluorine chemical parks, named as Fuxin
Haizhou District fluorine chemical industry park (park I) and Fuxin Fumeng Yi Matu fluorine chemical industry park (park II), with many fluorinated chemical manufacturers inside. As previously discussed, these two fluorine chemical parks were dominant point sources of PFASs in water samples of zone B and zone $\mathrm{C}$. To further identify the sources, we analyzed seasonal and yearly production capacities of major fluorinated chemical manufacturers in these two parks (Fig. 2). Major fluorinated chemicals produced in these two fluorine chemical industry parks were polytetrafluoroethylene (PTFE), fluorocarbon alcohol, hydrofluoroether, fluorinated intermediates, tetrafluoro coatings, and other organic/inorganic fluorine products. The statistic data were collected from Liaoning Statistical Information Net (http://www.ln.stats.gov.cn), China Fluorine Plastic Net (http://www.myptfe.com), and Liaoning Statistical Yearbook (NBS 2012, 2013). The highest total production capacity of fluorinated chemicals was found in summer, followed by spring and autumn, while the lowest capacity was found in winter (Fig. 2). The distribution patterns of PFASs in seasonal water samples of zone B and zone $\mathrm{C}$ were consistent with this observed production capacity trend, confirming that the emissions of these fluorinated chemical manufacturers were the main direct sources of PFASs along the Daling River. Bao et al. (2010) reported the high level of PFOA in the effluent water released from one of these parks in 2010. Wang et al. (2013) investigated the production and use of organic fluorine compounds of the two parks by 2011 and found that organic fluorine products, such as PFBA, PFOA, KPFBS, PFBSF, and perfluorooctanoic acid ammonium salt (APFO), are produced by ECF of the two parks, explaining the high level of PFBA, PFBS, and PFOA in those areas. All the previous studies as well as our present study suggested that the direct local input was the most important contamination source in the study area.

Besides the direct wastewater discharge, urban runoff is another significant source of PFASs to surface water (Xiao et al. 2012). As one of the most effective way to clean up particulate matters in air and atmospheric pollutants, precipitation can also dissolve and remove PFASs in solid particles of surface ground (Al-Khashman 2005; Migliavacca et al. 2005; Zhao et al. 2013). Liaoning Province has a relative higher rainfall in summer and autumn compared with spring and winter. Therefore, the high PFAS concentration in water samples of summer and autumn could also be attributed to the frequent rainfall scour of the watershed.

Volatile and semi-volatile PFAS precursors, such as fluorotelomer alcohols (FTOHs), fluorotelomer olefins (FTOs), and fluorosulfonamido alcohols (FSAs), can be long-range atmospheric transported by air movements. The degradation of these precursors into ionic PFCAs and PFSAs has been suggested as potential sources of PFASs in the environment, especially in remote area (Kwok et al. 2013; Young et al. 2007). It is prohibited to discharge wastewaters into the 


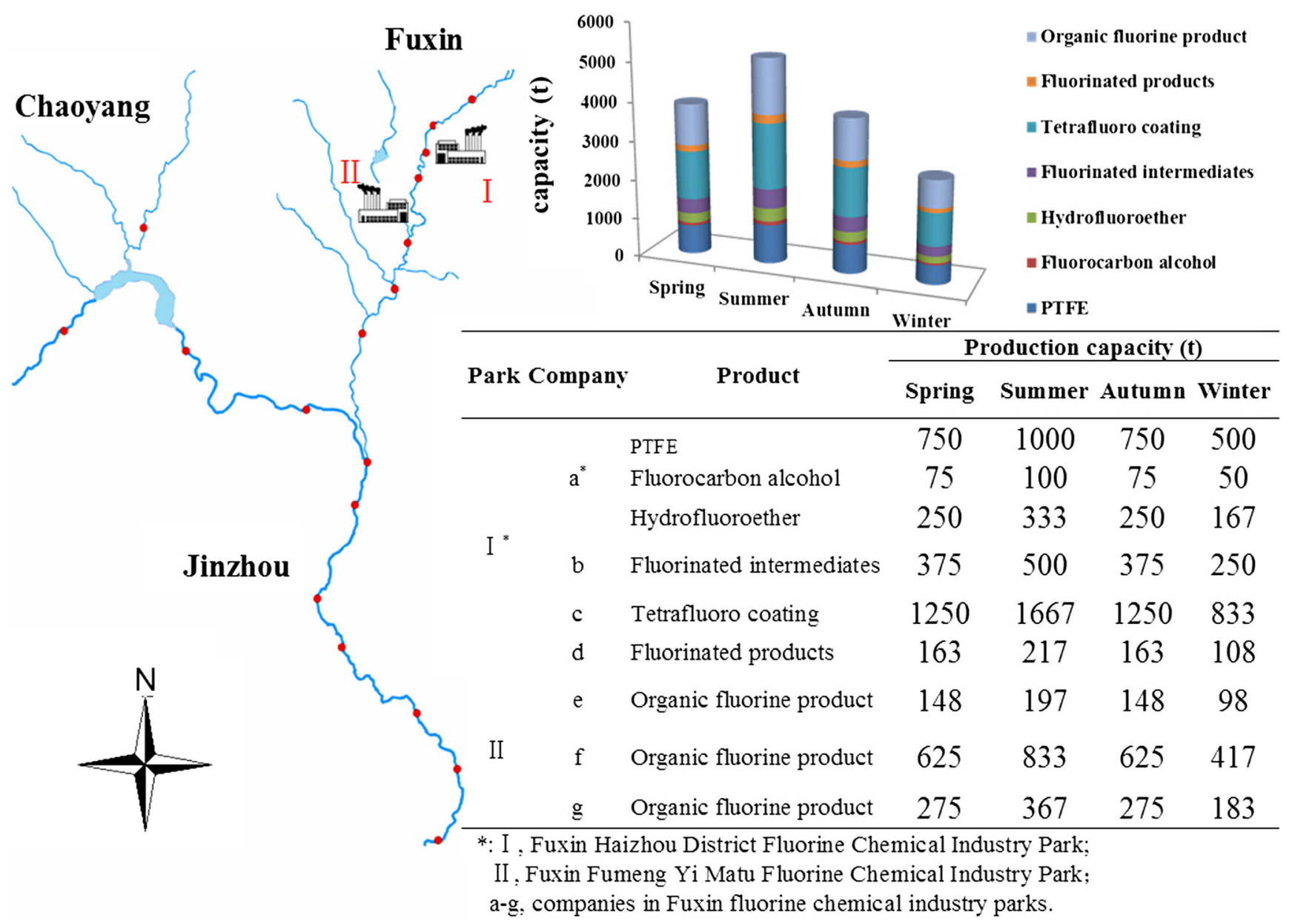

Fig. 2 Production capacities of main fluorinated chemicals in the study area

Bashi Reservoir in zone $\mathrm{D}$, which is a reserved drinking water resource. However, detectable concentration and distribution of PFOS in surface water of this region were found in this study. Moreover, the use of fossil fuels in winter added the amount of particulate matters in air, which might carry PFAS precursors and transport them to remote area. Therefore, the PFOS in surface water of zone D might come from atmospheric sources.

Mass flux estimation of PFASs into the Bohai Sea

We hypothesized that the water discharge and concentrations of PFASs in water were stable, and the emissions of industrial parks were continuous during the whole season (Xie et al. 2013a, b). Based on this hypothesis, seasonal riverine PFAS mass flows were roughly estimated according to the PFAS concentrations and water discharge data detected in the present study. Therefore, the mass flows determined in this study were preliminary estimations. Table S3a-d and Fig. 3 summarize the daily mass flows of individual and total PFASs in different seasons. The daily mass flows of PFASs ranged from $5.28 \mathrm{E}-04$ to $0.91 \mathrm{~kg} \mathrm{day}^{-1}$ in spring, from $3.77 \mathrm{E}-03$ to $4.10 \mathrm{~kg} \mathrm{day}^{-1}$ in summer, from $4.60 \mathrm{E}-04$ to $0.76 \mathrm{~kg} \mathrm{day}^{-1}$ in autumn, and from $1.83 \mathrm{E}-05$ to $0.23 \mathrm{~kg} \mathrm{day}^{-1}$ in winter, respectively. PFBS, PFBA, and PFOA had the dominant contribution to the total fluxes. The mass flows of PFASs were obviously increased from site 3 in all the four seasons and reached the highest value at site 9 in spring and winter, while the highest value was detected from site 10 and site 5 in summer and autumn, respectively.

Annual riverine mass flows of PFASs were calculated by summing the mass flows of PFASs in four seasons. The sum of annual mass flows of PFASs ranged from 0.44 to $509 \mathrm{~kg} \mathrm{year}^{-1}$, with PFBA, PFBS, and PFOA that ranged from 0.17 to $162 \mathrm{~kg} \mathrm{year}^{-1}$, from 0.04 to $230 \mathrm{~kg} \mathrm{year}^{-1}$, and from 0.08 to $89.0 \mathrm{~kg} \mathrm{year}^{-1}$, respectively (Table 2). At the coastal estuary, the mass loading of PFASs into the Bohai Sea from the Daling River was about $461 \mathrm{~kg}$ year $^{-1}$ (site 14), with individual mass flows of PFBA, PFBS, and PFOA of 138, 230 , and $59.6 \mathrm{~kg} \mathrm{year}^{-1}$, respectively.

Risk assessment of PFASs in water from the Daling River

Although the toxicity of PFASs has been intensively studied in recent years, most work has been limited to either PFOS or PFOA (Hekster et al. 2003; Wang et al. 2014b). It is known 

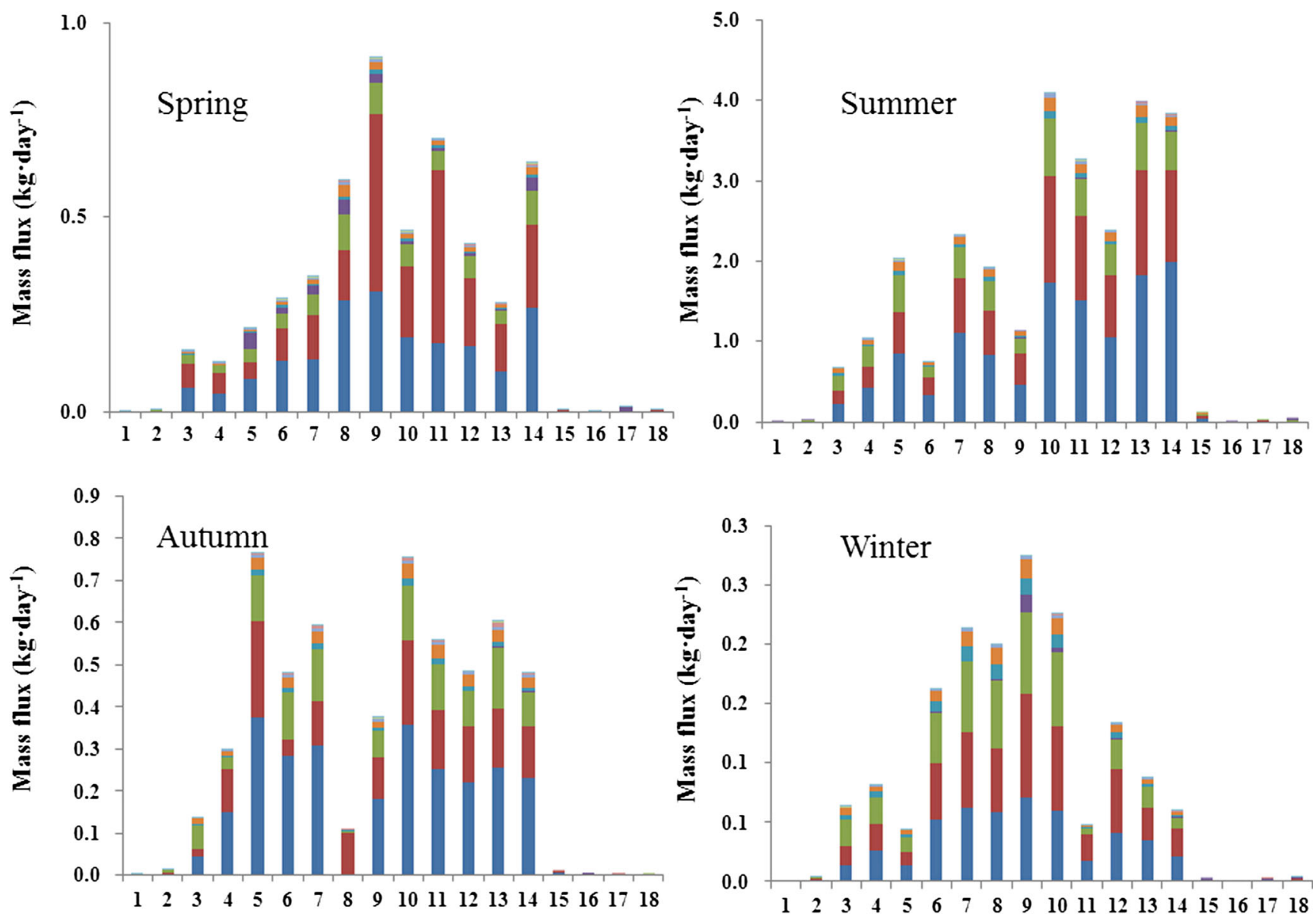

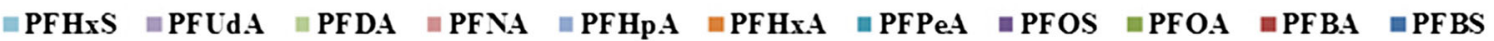

Fig. 3 Daily mass flux $\left(\mathrm{kg} \mathrm{day}^{-1}\right)$ of PFASs in the Daling River in different seasons

that PFOS has moderate acute toxicity and slight chronic toxicity to aquatic organisms and terrestrial animals. Therefore, the use of PFOS-based products was discontinued in 2000, and PFOS was listed in the Stockholm Convention in 2009. Recently, PFBS has been widely used as a substitute of PFOS due to its less accumulation and less toxicity, but studies still found toxicology information about it (Oliaei et al. 2013; Giesy et al. 2010).

It is quite necessary to establish quality criteria of PFAScontaining water to protect aquatic life. Giesy et al. (2010) derived the criteria maximum concentration (CMC) and criteria continuous concentration (CCC) of PFOS, PFOA, and PFBS for the protection of aquatic organisms in North America and also the avian wildlife value (AWV) of PFOS and PFBS for protection of wildlife. Yang et al. (2014) derived the CMC and CCC of PFOS and PFOA to protect aquatic organisms in China in 2014. All the detected concentrations of PFASs were below their corresponding CMC and CCC values in the present study (Fig. 4), exhibiting a low risk to aquatic organisms in the Daling River. However, the PFOS concentrations in some water samples in spring exceeded the
PFOS AWV value ( $\left.47 \mathrm{ng} \mathrm{L}^{-1}\right)$, indicating that PFOS in spring water might have potential risk to wildlife in the Daling River.

The Baishi Reservoir has been served as a drinking water source of Fuxin City for years, and its water quality directly affects the health of human in Fuxin City. Nowadays, drinking water criteria of PFASs have been established in many countries, including America (EPA Provisional Health Advisory, PFOS $200 \mathrm{ng} \mathrm{L}^{-1}$, PFOA 400 ng L ${ }^{-1}$; Minnesota Health Risk Limits, PFOS $300 \mathrm{ng} \mathrm{L}{ }^{-1}$, PFOA $300 \mathrm{ng} \mathrm{L}^{-1}$, PFBS $7000 \mathrm{ng} \mathrm{L}^{-1}$, PFBA 7000 ng L ${ }^{-1}$; New Jersey, PFOA 40 ng L ${ }^{-1}$ ), Germany (PFOS 100 ng L ${ }^{-1}$, PFOA $100 \mathrm{ng} \mathrm{L}^{-1}$, PFBS 3000 ng L ${ }^{-1}$, PFBA $7000 \mathrm{ng} \mathrm{L}^{-1}$ ), and Canada (PFOS 300 ng L ${ }^{-1}$, PFOA 700 ng L ${ }^{-1}$ ) (USEPA 2009; MDH 2008; Post et al. 2009). All the concentrations detected in the Baishi Reservoir area were below those drinking water criteria, suggesting that the PFASs in water from the Baishi Reservoir had little risk to citizens. Although the water in the Xi River and downstream of the Daling River was not used as drinking water, it could also affect the quality of groundwater, which was widely used as drinking water in North China. Concentrations of PFBS in summer water of site $4\left(3870 \mathrm{ng} \mathrm{L}{ }^{-1}\right)$ 
Table 2 Annual riverine mass flow $\left(\mathrm{kg} \mathrm{year}^{-1}\right.$ ) of PFASs in the Daling River

\begin{tabular}{|c|c|c|c|c|c|c|c|c|c|c|c|c|}
\hline & PFBS & PFBA & PFOA & PFOS & PFPeA & PFHxA & PFHpA & PFNA & PFDA & PFUdA & PFHxS & $\Sigma$ PFASs \\
\hline 1 & 0.07 & 0.51 & 0.69 & 0.19 & 0.03 & 0.05 & 0.06 & 0.01 & 0.00 & 0.00 & 0.00 & 1.60 \\
\hline 2 & 0.32 & 1.58 & 1.10 & 0.01 & 0.03 & 0.07 & 0.07 & 0.01 & 0.00 & 0.00 & 0.00 & 3.19 \\
\hline 3 & 32.2 & 24.0 & 26.2 & 0.04 & 3.18 & 7.00 & 1.35 & 0.12 & 0.18 & 0.00 & 0.05 & 94.3 \\
\hline 4 & 58.9 & 40.7 & 29.1 & 0.07 & 3.59 & 6.98 & 1.59 & 0.18 & 0.26 & 0.01 & 0.06 & 142 \\
\hline 5 & 121 & 72.9 & 56.1 & 3.98 & 6.79 & 13.6 & 3.12 & 0.65 & 0.39 & 0.02 & 0.11 & 279 \\
\hline 6 & 72.7 & 35.8 & 30.1 & 1.53 & 3.73 & 6.90 & 1.68 & 0.56 & 0.29 & 0.01 & 0.05 & 153 \\
\hline 7 & 147 & 88.3 & 56.9 & 2.40 & 6.91 & 13.2 & 2.91 & 1.06 & 0.46 & 0.01 & 0.10 & 319 \\
\hline 8 & 108 & 76.9 & 48.4 & 3.62 & 6.41 & 12.3 & 2.59 & 0.87 & 0.30 & 0.01 & 0.11 & 259 \\
\hline 9 & 94.4 & 94.2 & 36.6 & 3.80 & 4.97 & 9.41 & 2.13 & 0.83 & 0.29 & 0.04 & 0.05 & 247 \\
\hline 10 & 215 & 162 & 89.0 & 1.52 & 10.9 & 21.9 & 5.13 & 1.75 & 0.54 & 0.08 & 0.21 & 509 \\
\hline 11 & 180 & 152 & 58.2 & 1.39 & 7.34 & 14.7 & 3.50 & 1.43 & 0.48 & 0.08 & 0.11 & 419 \\
\hline 12 & 137 & 103 & 50.8 & 1.38 & 6.07 & 12.5 & 2.97 & 1.08 & 0.33 & 0.03 & 0.10 & 315 \\
\hline 13 & 204 & 146 & 71.6 & 0.91 & 8.20 & 17.0 & 4.00 & 2.16 & 0.70 & 0.08 & 0.03 & 455 \\
\hline 14 & 230 & 138 & 59.6 & 6.04 & 6.89 & 13.2 & 3.71 & 2.20 & 0.58 & 0.11 & 0.18 & 461 \\
\hline 15 & 3.88 & 4.43 & 2.01 & 0.36 & 0.29 & 0.49 & 0.23 & 0.23 & 0.03 & 0.01 & 0.00 & 12.0 \\
\hline 16 & 0.04 & 0.17 & 0.08 & 0.07 & 0.01 & 0.01 & 0.01 & 0.02 & 0.01 & 0.01 & 0.00 & 0.44 \\
\hline 17 & 0.18 & 1.41 & 0.53 & 1.29 & 0.06 & 0.08 & 0.09 & 0.13 & 0.03 & 0.00 & 0.00 & 3.82 \\
\hline 18 & 0.17 & 1.73 & 0.35 & 2.15 & 0.06 & 0.07 & 0.06 & 0.10 & 0.03 & 0.02 & 0.00 & 4.74 \\
\hline
\end{tabular}

exceeded the drinking water criteria of Germany (3000 ng L ${ }^{-1}$ ), while concentrations of PFBA and PFBS of other samples were all below these drinking water criteria. High concentrations of PFOS were found in spring water
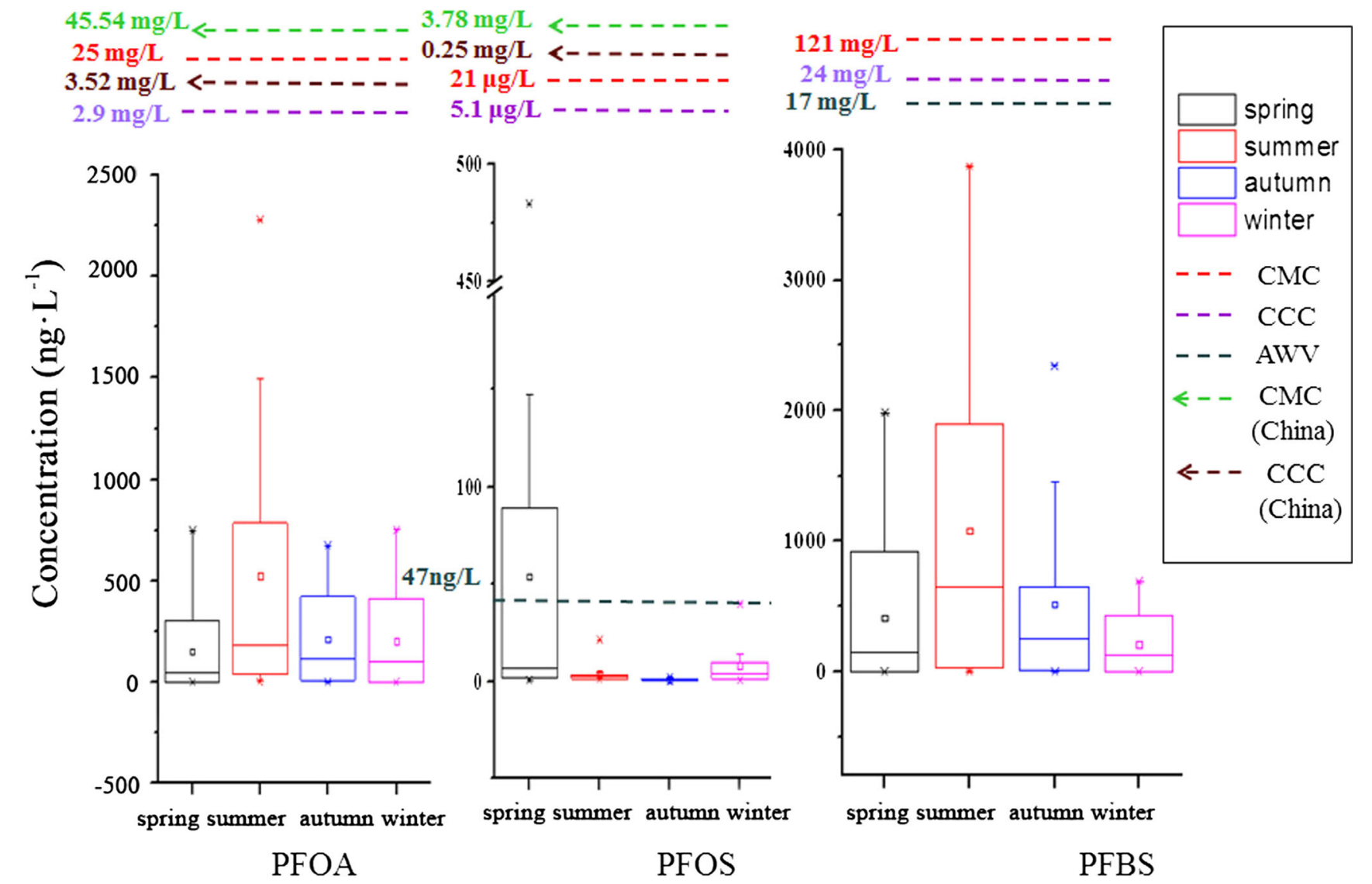

Fig. 4 Comparison of PFAS concentrations with relative Water Quality Criteria

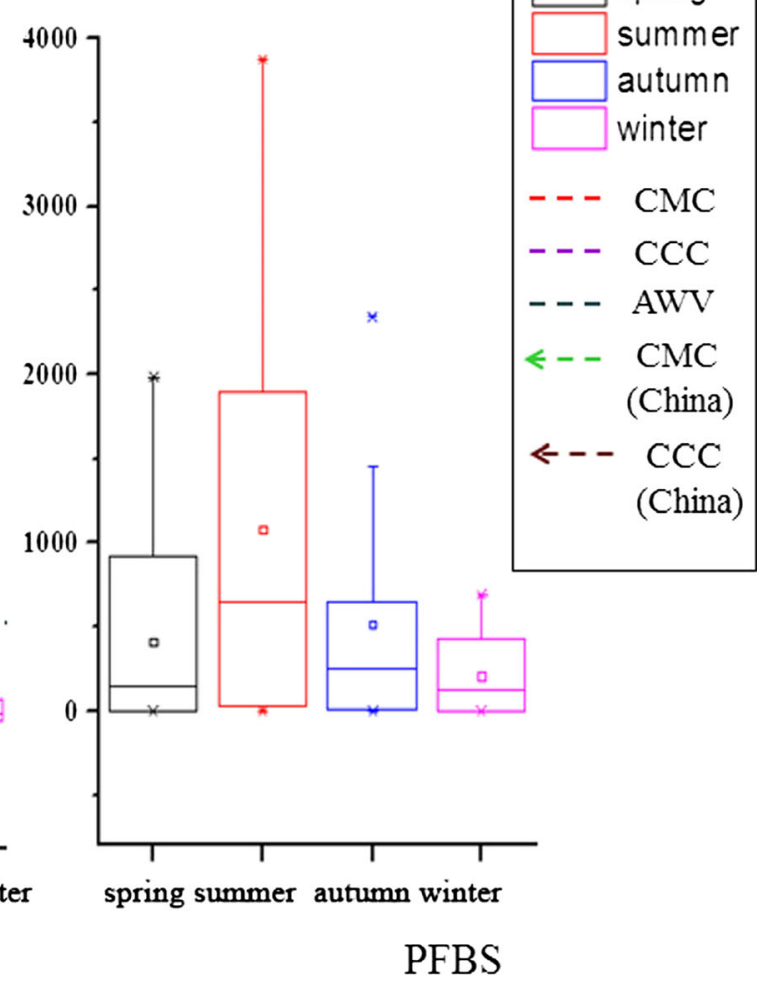


samples, its highest concentration (site 5, $483 \mathrm{ng} \mathrm{L}^{-1}$ ) exceeded all the abovementioned drinking water criteria, and its concentrations of other three sites (sites 6, 7, and 8) exceeded the drinking water criteria of Germany $\left(100 \mathrm{ng} \mathrm{L}^{-1}\right)$ as well. Moreover, the concentration of PFOA exceeded the criteria of New Jersey in most of the sites, it exceeded the criteria of Germany in above half of the sites, and it exceeded the criteria of Canada in some sites. This indicated that PFOA had a relative high potential risk to the health of citizens in the study area. According to Minnesota Department of Health, a sum of hazard quotients called "hazard index" was used to determine the health risk when multiple chemicals were present (the hazard index exceeding 1 indicates the existence of risk, Minnesota Department of Health). Table S4 shows the calculated hazard index of PFASs in this study. The multiple health risk of PFASs was high in the Xi River (zone B in Fig. S1), while the multiple health risk of PFASs was low in other river reaches.

\section{Conclusions}

Concentrations and composition profiles of PFASs in the Daling River varied in different seasons. In general, the average concentrations of $\Sigma$ PFASs and dominant homologues, such as PFBS, PFBA, and PFOA, were the highest in summer water samples, followed by autumn, spring, and winter. Contributions of PFBS, PFBA, and PFOA reached approximately $90 \%$ of total PFAS concentrations. Source identification suggested that the two fluorine chemical industry parks in the study area were dominant contamination sources of PFASs. The annual mass loading of $\triangle$ PFASs into the Bohai Sea from the Daling River reached $461 \mathrm{~kg}$ year ${ }^{-1}$, with individual mass flows of PFBA, PFBS, and PFOA of 138, 230, and $59.6 \mathrm{~kg} \mathrm{year}^{-1}$, respectively. Basically, concentrations of most PFASs in the study area had little risk to aquatic organisms and wildlife, while concentrations of PFOS in spring water might have potential risk to wildlife in the Daling River.

Acknowledgments This study was supported by the National Natural Science Foundation of China under Grant No. 41171394, the National Fundamental Field Study Program with Grant No. 2013FY11110, and the Key Research Program of the Chinese Academy of Sciences under Grant No. KZZD-EW-TZ-12. We would like to thank the editors and reviewers for their valuable comments and suggestions.

\section{References}

Ahrens L (2011) Polyfluoroalkyl compounds in the aquatic environment: a review of their occurrence and fate. J Environ Monit 13:20-31

Ahrens L, Shoeib M, Harner T, Lee SC, Guo R, Reiner EJ (2011) Wastewater treatment plant and landfills as sources of polyfluoroalkyl compounds to the atmosphere. Environ Sci Technol 45:8098-8105

Al-Khashman OA (2005) Study of chemical composition in wet atmospheric precipitation in Eshidiya area. Jordan Atmos Environ 39: 6175-6183

Bao J, Liu W, Liu L, Jin Y, Ran X, Zhang Z (2010) Perfluorinated compounds in urban river sediments from Guangzhou and Shanghai of China. Chemosphere 80:123-130

Bao J, Liu W, Liu L, Jin Y, Dai J, Ran X, Zhang Z, Tsuda S (2011) Perfluorinated compounds in the environment and the blood of residents living near fluorochemical plants in Fuxin, China. Environ Sci Technol 45:8075-8080

Chen CL, Wang TY, Khim JS, Luo W, Jiao WT, Lu YL, Naile JE, Hu WY, Zhang X, Geng J, Bi CC, Li J, Giesy JP (2011) Perfluorinated compounds in water and sediment from coastal regions of the northern Bohai Sea, China. Chem Ecol 27:165-176

Dreyer A, Weinberg I, Temme C, Ebinghaus R (2009) Polyfluorinated compounds in the atmosphere of the Atlantic and Southern Oceans: evidence for a global distribution. Environ Sci Technol 43:65076514

EPC (2006) Directive 2006/122/EC of the European parliament and of the council of 12 December 2006 amending for the 30th time Council Directive 76/769/EEC on the approximation of the laws, regulations and administrative provisions of the Member States relating to restrictions on the marketing and use of certain dangerous substances and preparations (perfluorooctane sulfonates). European Parliament and Council, Strasbourg

Eschauzier C, Haftka J, Stuyfzand PJ, De Voogt P (2012) Perfluorinated compounds in infiltrated river rhine water and infiltrated rainwater in coastal dunes. Environ Sci Technol 44:7450-7455

Giesy JP, Kannan K (2002) Peer reviewed: perfluorochemical surfactants in the environment. Environ Sci Technol 36:146A-152A

Giesy J, Naile J, Khim J, Jones P, Newsted J (2010) Aquatic toxicology of perfluorinated chemicals, reviews of environmental contamination and toxicology. Springer, New York, pp 1-52

Hekster F, Laane RPM, Voogt P (2003) Environmental and toxicity effects of perfluoroalkylated substances, reviews of environmental contamination and toxicology. Springer, New York, pp 99-121

Houde M, De Silva AO, Muir DCG, Letcher RJ (2011) Monitoring of perfluorinated compounds in aquatic biota: an updated review. Environ Sci Technol 45:7962-7973

Jin YH, Liu W, Sato I, Nakayama SF, Sasaki K, Saito N, Tsuda S (2009) PFOS and PFOA in environmental and tap water in China. Chemosphere 77:605-611

Kwok KY, Yamazaki E, Yamashita N, Taniyasu S, Murphy MB, Horii Y, Petrick G, Kallerborn R, Kannan K, Murano K, Lam PK (2013) Transport of perfluoroalkyl substances (PFAS) from an arctic glacier to downstream locations: implications for sources. Sci Total Environ 447:46-55

Lange FT, Wenz M, Schmidt CK, Brauch HJ (2007) Occurence of perfluoroalkyl sulfonates and carboxylates in German drinking water sources compared to other countries. Water Sci Technol 56:151158

Lau C, Butenhoff JL, Rogers JM (2004) The developmental toxicity of perfluoroalkyl acids and their derivatives. Toxicol Appl Pharmacol 198:231-241

Li F, Sun H, Hao Z, He N, Zhao L, Zhang T, Sun T (2011) Perfluorinated compounds in Haihe River and Dagu Drainage Canal in Tianjin, China. Chemosphere 84:265-271

Liaoning Bureau of statistics (NBS) (2012) Liaoning statistical yearbook. China Statistics Press, Beijing

Liaoning Bureau of statistics (NBS) (2013) Liaoning statistical yearbook. China Statistics Press, Beijing

Liu J, Li J, Luan Y, Zhao Y, Wu Y (2009) Geographical distribution of perfluorinated compounds in human blood from Liaoning Province, China. Environ Sci Technol 43:4044-4048 
McLachlan MS, Holmström KE, Reth M, Berger U (2007) Riverine discharge of perfluorinated carboxylates from the European Continent. Environ Sci Technol 41(21):7260-7265

Migliavacca D, Teixeira EC, Wiegand F, Machado ACM, Sanchez J (2005) Atmospheric precipitation and chemical composition of an urban site, Guaíba hydrographic basin, Brazil. Atmos Environ 39: $1829-1844$

Minnesota Department of Health (MDH) (2008) Health risk limits for perfluorochemicals

Möller A, Ahrens L, Surm R, Westerveld J, van der Wielen F, Ebinghaus R, de Voogt P (2010) Distribution and sources of polyfluoroalkyl substances (PFAS) in the River Rhine watershed. Environ Pollut 158(10):3243-3250

Naile JE, Khim JS, Wang T, Chen C, Luo W, Kwon B-O, Park J, Koh CH, Jones PD, Lu Y, Giesy JP (2010) Perfluorinated compounds in water, sediment, soil and biota from estuarine and coastal areas of Korea. Environ Pollut 158:1237-1244

OECD (2002) Hazard assessment of perfluorooctane sulfonate (PFOS) and its salts. Organization for Economic Co-operation and Development; November 21

Oliaei F, Kriens D, Weber R, Watson A (2013) PFOS and PFC releases and associated pollution from a PFC production plant in Minnesota (USA). Environ Sci Pollut R 20:1977-1992

Olsen GW, Butenhoff JL, Zobel LR (2009) Perfluoroalkyl chemicals and human fetal development: an epidemiologic review with clinical and toxicological perspectives. Reprod Toxicol 27:212-230

Pan Y, Shi Y, Wang J, Jin X, Cai Y (2011) Pilot investigation of perfluorinated compounds in river water, sediment, soil and fish in Tianjin, China. Bull Environ Contam Toxicol 87:152-157

Paul AG, Jones KC, Sweetman AJ (2009) A first global production, emission, and environmental inventory for Perfluorooctane Sulfonate. Environ Sci Technol 43(2):386-392

Pistocchi A, Loos R (2009) A map of European emissions and concentrations of PFOS and PFOA. Environ Sci Technol 43:9237-9244

Post GB, Louis JB, Cooper KR, Boros-Russo BJ, Lippincott RL (2009) Occurrence and potential significance of perfluorooctanoic acid (PFOA) detected in New Jersey public drinking water systems. Environ Sci Technol 43(12):4547-4554

Prevedouros K, Cousins IT, Buck RC, Korzeniowski SH (2006) Sources, fate and transport of perfluorocarboxylates. Environ Sci Technol 40: $32-44$

Shi Y, Pan Y, Wang J, Cai Y (2012) Distribution of perfluorinated compounds in water, sediment, biota and floating plants in Baiyangdian Lake, China. J Environ Monit 14:636-642

Skutlarek D, Exner M, Färber H (2006) Perfluorinated surfactants in surface and drinking waters. Environ Sci Pollut Res 13:299-307

So MK, Miyake Y, Yeung WY, Ho YM, Taniyasu S, Rostkowski P, Yamashita N, Zhou BS, Shi XJ, Wang JX, Giesy JP, Yu H, Lam PK (2007) Perfluorinated compounds in the Pearl River and Yangtze River of China. Chemosphere 68:2085-2095

Theobald N, Caliebe C, Gerwinski W, Huhnerfuss H, Lepom P (2012) Occurrence of perfluorinated organic acids in the North and Baltic Seas. Part 2: distribution in sediments. Environ Sci Pollut Res 19: 313-324

Tsuda T, Inoue A, Igawa T, Tanaka K (2010) Seasonal changes of PFOS and PFOA concentrations in Lake Biwa Water. Bull Environ Contam Toxicol 85:593-597

UNEP (2009) The conference of the parties 4 of the Stockholm Convention (COP-4) in Geneva placed perfluorooctane sulfonate and perfluorooctane sulfonyl fluoride (PFOS and PFOSF) in Annex B. Stoekholm Convention on Persistent organic Pollutants (POPs)

US Environmental Protection Agency (USEPA) (2006) 2010/2015 PFOA stewardship program
USEPA (2009) Provisional health advisories for perfluorooctanoic acid (PFOA) and perfluorooctane sulfonate (PFOS), USEPA Office of Water

Vierke L, Staude C, Biegel-Engler A, Drost W, Schulte C (2012) Perfluorooctanoic acid (PFOA) - main concerns and regulatory developments in Europe from an environmental point of view. Environ Sci Eur 24:16

Wang T, Wang YW, Liao CY, Cai YQ, Jiang GB (2009) Perspectives on the inclusion of perfluorooctane sulfonate into the Stockholm Convention on persistent organic pollutants. Environ Sci Technol 43:5171-5175

Wang TY, Lu YL, Chen CL, Naile JE, Khim JS, Park J, Luo W, Jiao WT, Hu WY, Giesy JP (2011) Perfluorinated compounds in estuarine and coastal areas of north Bohai Sea, China. Mar Pollut Bull 62:19051914

Wang TY, Khim JS, Chen CL, Naile JE, Lu YL, Kannan K, Park J, Luo W, Jiao WT, Hu WY, Giesy JP (2012) Perfluorinated compounds in surface waters from Northern China: comparison to level of industrialization. Environ Int 42:37-46

Wang P, Wang TY, Giesy JP, Lu YL (2013) Perfluorinated compounds in soils from Liaodong Bay with concentrated fluorine industry parks in China. Chemosphere 91:751-757

Wang P, Lu YL, Wang TY, Fu YN, Zhu ZY, Liu SJ, Xie SW, Xiao Y, Giesy JP (2014a) Occurrence and transport of 17 perfluoroalkyl acids in 12 coastal rivers in south Bohai coastal region of China with concentrated fluoropolymer facilities. Environ Pollut 190:115-122

Wang TY, Wang P, Meng J, Liu SJ, Lu YL, Khim JS, Giesy PJ (2014b) A review of sources, multimedia distribution and health risks of perfluoroalkyl acids (PFAAs) in China. Chemosphere. doi:10. 1016/j.chemosphere.2014.09.021

Xiao F, Simcik MF, Gulliver JS (2012) Perfluoroalkyl acids in urban stormwater runoff: influence of land use. Water Res 46:6601-6608

Xie SW, Lu YL, Wang TY, Liu SJ, Jones KC, Sweetman AJ (2013a) Estimation of PFOS emission from domestic sources in the eastern coastal region of China. Environ Int 59:336-343

Xie SW, Wang TY, Liu SJ, Jones KC, Sweetman AJ, Lu YL (2013b) Industrial source identification and emission estimation of perfluorooctane sulfonate in China. Environ Int 52:1-8

Yamashita N, Kannan K, Taniyasu S, Horii Y, Petrick G, Gamo T (2005) A global survey of perfluorinated acids in oceans. Mar Pollut Bull 51:658-668

Yang S, Xu F, Wu F, Wang S, Zheng B (2014) Development of PFOS and PFOA criteria for the protection of freshwater aquatic life in China. Sci Total Environ 470-471:677-683

Young CJ, Furdui VI, Franklin J, Koerner RM, Muir DCG, Mabury SA (2007) Perfluorinated acids in arctic snow: new evidence for atmospheric formation. Environ Sci Technol 41:3455-3461

Zhang W, Zhang Y, Taniyasu S, Yeung LWY, Lam PKS, Wang J, Li X, Yamashita N, Dai J (2013) Distribution and fate of perfluoroalkyl substances in municipal wastewater treatment plants in economically developed areas of China. Environ Pollut 176:10-17

Zhao L, Zhou M, Zhang T, Sun H (2013) Polyfluorinated and perfluorinated chemicals in precipitation and runoff from cities across Eastern and Central China. Arch Environ Contam Toxicol 64:198-207

Zhao Z, Xie Z, Tang J, Sturm R, Chen Y, Zhang G, Ebinghaus R (2014) Seasonal variations and spatial distributions of perfluoroalkyl substances in the rivers Elbe and lower Weser and the North Sea. Chemosphere. doi:10.1016/j.chemosphere.2014.03.050

Zushi Y, Masunaga S (2009) Identifying the nonpoint source of perfluorinated compounds using a geographic information system based approach. Environ Toxicol Chem 28:691-700 